Relations industrielles

Industrial Relations

\title{
Politics and the Labor Movement in Chile, by Alan Angell, London, Oxford University Press, 1972, 289 pp.
}

\section{Jean Boivin}

Volume 29, numéro 4, 1974

URI : https://id.erudit.org/iderudit/028567ar

DOI : https://doi.org/10.7202/028567ar

Aller au sommaire du numéro

Éditeur(s)

Département des relations industrielles de l'Université Laval

ISSN

0034-379X (imprimé)

1703-8138 (numérique)

Découvrir la revue

Citer ce compte rendu

Boivin, J. (1974). Compte rendu de [Politics and the Labor Movement in Chile, by Alan Angell, London, Oxford University Press, 1972, 289 pp.] Relations industrielles / Industrial Relations, 29(4), 886-887.

https://doi.org/10.7202/028567ar

Tous droits réservés @ C Département des relations industrielles de l'Université Laval, 1974
Ce document est protégé par la loi sur le droit d'auteur. L'utilisation des services d'Érudit (y compris la reproduction) est assujettie à sa politique d'utilisation que vous pouvez consulter en ligne.

https://apropos.erudit.org/fr/usagers/politique-dutilisation/ 
aux pièces est la règle générale, et lorsque certains travailleurs réussissent à accroître leurs gains, on se hâte d'accroître le fardeau de la tâche. Comme cette période est marquée par une certaine poussée inflationniste, le salaire réel des employés laisse donc beaucoup à désirer, ce qui faisait dire au surintendant d'une usine «Il est de beaucoup préférable qu'elles (les femmes) travaillent et puissent manger trois fois par jour plutôt que de rester à la maison et mourir de faim $\gg$.

Il était normal dans de pareilles conditions que le syndicalisme naissant cherche à s'implanter dans les usines et qu'il y ait eu même à cette époque des confits assez douloureux. L'auteur consacre à ce sujet les deux chapitres de son travail. Successivement, trois organisations furent actives dans ce secteur: les Chevaliers du Travail d'abord, l'Union ouvrière fédérale 7387 , syndicat interprofessionnel dont le président est un cultivateur et le secrétaire, un employé de canal et, enfin, la Fédération des ouvriers textiles du Canada qui est une association indépendante. Outre leurs conflits internes et la mauvaise réputation du syndicalisme dans l'opinion publique, il n'est pas surprenant que l'opposition systématique des employeurs ait eu raison d'un mouvement syndical faible et très peu structuré. Ceci ne signifie pas pour autant qu'il n'y ait pas eu de grèves. L'auteur en décrit quatre : l'une à Magog en juillet 1900, qui fut suivie d'une deuxième à Montmorency quelques jours plus tard; deux autres à Montréal aux usines d'Hochelaga et de St-Henri. Ces grèves revêtent pour la plupart un caractère spontané, d'où un manque de concertation nuisible. Comme d'une façon générale, l'industrie s'est développée dans des petites agglomérations ou les banlieues de villes plus importantes, qu'elle est dans ces milieux à peu près la seule occasion valable d'emplois et dont la petite bourgeoisie en tire dans une large mesure sa prospérité, il s'ensuit que celle-ci, redoutant de perdre certains avantages, se montrait fort réticente face à ces conflits et cédaient volontiers aux pressions des compagnies, même si les travailleurs acceptaient généralement avec bienveillance la médiation des notables du lieu.

Cette courte étude mérite de retenir l'attention: elle est bien charpentée; elle est bien documentée. Elle peut donc être considérée comme un apport très valable à l'histoire de la vie économique et sociale du Québec qui reste à faire. Il faudrait un plus grand nombre de ces monographies nettement délimitées dans le temps et dans l'espace qui sont autant de pièces essentielles à la composition d'un tableau d'ensemble.

\section{André ROY}

Ministère du travail et de

la main-d'œvre, Québec

\section{Polititics and the Labor Movement in Chile, by Alan Angell, London, Oxford University Press, 1972, $289 \mathrm{pp}$.}

Ce livre tente d'analyser les relations entre les syndicats et les partis politiques au Chili. Les trois premiers chapitres sont consacrés à l'historique du mouvement syndical, à l'analyse de ses structures et de son fonctionnement ainsi qu'à la description des contextes juridiques et socio-économiques à l'intérieur desquels le système de relations industrielles évolue. Les quatre chapitres suivants consistent en une analyse structurelle et historique des quatre principaux partis politiques chiliens : le parti communiste, le parti socialiste, le parti chrétien-démocrate et le parti radical. Enfin, le dernier chapitre est consacré à l'analyse plus systématique des relations entre la principale centrale syndicale «Central Unica de Trabajadores $\gg$ et les partis politiques.

Politics and the Labor Movement In Chile est à la fois intéressant et décevant. Le livre d'Angell est intéressant car on y retrouve une description systématique des principaux acteurs en présence à savoir les organisations syndicales et les partis politiques. Ainsi, les trois premiers chapitres consacrés au mouvement syndical nous révèlent les principales raisons expliquant les forces et les faiblesses de celui-ci. En effet, l'existence d'un système de relations industrielles très décentralisé favorise et nuit simultanément au développement de l'organisation syndicale. D'une part, la législation prévoit que si un syndicat regroupe plus de $55 \%$ des ouvriers d'une entreprise, l'ensemble des salariés doivent faire partie du syndicat. Par contre, la même législation empêche les regroupements syndicaux à un niveau autre que celui 
de l'entreprise, sauf dans le cas des «ouvriers》 qui, par opposition aux "employés», peuvent se grouper en fédération. De plus, les syndicats d'employés du secteur public sont interdits. Quant aux travailleurs des mines de cuivre, ils jouissent d'un statut particulier.

La législation du travail qui fut adoptée en 1924 et amendée par la suite sous le régime chrétien-démocrate de Frei comporte bien d'autres contraintes à l'endroit des syndicats, notamment l'interdiction de la constitution de fonds de grève séparés, l'examen régulier des budgets des organisations syndicales par des inspecteurs du travail, le financement de syndicats industriels à raison de $50 \%$ par les profits de l'entreprise, ce qui favorise l'existence de syndicats dominés par les employeurs ainsi que l'interdiction pour les syndicats d'investir leurs fonds.

D'après Angell, cette législation du travail, dont les principes fondamentaux n'ont jamais été altérés, avait pour but de détruire le militantisme syndical, en confinant strictement la négociation collective au niveau de l'entreprise et en empêchant toute forme d'alliance entre les syndicats. Le résultat pratique fut double: d'une part, des alliances informelles se sont néanmoins constitués et les employés du secteur public font partie de syndicats illégaux mais tolérés. De plus des fédérations et des confédérations de travailleurs qui devraient être interdites existent maintenant au grand jour et sont également tolérées par le gouvernement. (Il est à noter que ce livre fut écrit avant l'arrivée au pouvoir de Salvador Allende. Celui-ci n'a d'ailleurs pas pu libéraliser la législation du travail après son arrivée au pouvoir à cause de la position minoritaire de la gauche au Congrès). D'autre part, les contraintes structurelles imposées au développement des syndicats ont favorisé leur politisation. C'est pourquoi la plupart des dirigeants et des militants syndicaux sont également très actifs à l'intérieur des partis politiques (surtout le parti communiste et le parti socialiste) et ils utilisent leur influence à l'intérieur du mouvement syndical pour tenter de rallier les travailleurs derrière des objectifs politiques spécifiques.

L'analyse des quatre principaux partis politiques révèle que l'auteur était certainement bien documenté mais elle comporte une multitude de détails historiques qui rendent la compréhension très difficile pour le lecteur non familier avec l'expérience chilienne. De plus, le manque de synthèse lors de la présentation des partis politiques nous empêche d'apprécier à leur juste valeur les récents événements politiques et le rôle qu'ont $\mathrm{pu} \mathrm{y}$ jouer les syndicats.

Une contribution importante du livre d'Angell est sans doute d'apporter un témoignage assez clair en faveur de la nécessité pour les syndicats de s'unir derrière un parti politique (ou une coalition de partis) s'ils veulent parvenir à opérer les transformations sociales et les modifications appropriées à la législation du travail qu'ils désirent. La victoire d'Allende en 1970 de même que sa chute en 1973 en sont deux exemples fort convainquants.

Une autre conséquence intéressante que l'on peut tirer de l'expérience du Chili est l'inévitable politisation des syndicats lorsque les problèmes qui confrontent leurs membres ne peuvent plus être résolus au niveau de la convention collective.

Université Laval

Jean BOIVIN

The Saul Wallen Papers: A Neutral's Contribution to Industrial Peace, colligé par Brown Yaffe, Ithaca. Cornell Studies in Industrial and Labor Relations no 18, 1974, $232 \mathrm{pp}$.

La vie professionnelle de Saul Wallen, éminent arbitre des conflits du travail aux Etats-Unis décédé en 1969, fut consacrée à la solution des conflits sociaux. Artisan de la Industrial Peace, il rendit quelque 5000 décisions, à titre d'arbitre de griefs, intervint aussi souvent à titre de conciliateur, d'enquêteur; vers la fin de sa vie, son action, jusque-là liée à la vie des entreprises industrielles, géantes et moyennes, se porta aussi sur l'amélioration des conditions de vie des minorités de la métropole américaine.

Le présent ouvrage est, à la fois, comme le personnage auquel il veut rendre hommage, chaleureux et constructif. Il présente l'homme et sa conception de la justice du travail syndiqué, grâce à ces 